\title{
Letters to the
}

\section{Editor}

\section{Effect of surgical case volume on outcome after the Norwood procedure \\ To the Editor:}

Checcia and colleagues ${ }^{1}$ analyzed outcome data for the Norwood procedure performed in a cohort of 29 institutions stratified by case volume using the Pediatric Health Information System. They conclude that survival is associated with institutional Norwood procedure volume and that regional referral centers should be established for care of children with hypoplastic left heart syndrome.

Table 1 from the article reveals that the most favorable outcome of the entire group occurred in an institution in the "low-volume" cohort and that 4 of the 5 institutions with the most favorable outcomes were in the low- and mediumvolume cohorts. Although variability in survival outcome is greater in lowvolume institutions viewed as a group (low volume, 25\%-100\% survival; higher volume, $55 \%-92 \%$ survival), it is evident that individual institutions can achieve excellent outcomes regardless of volume.

Mavroudis and Jacobs ${ }^{2}$ have stated that many lower-volume surgeons and centers have excellent results. Chang and Klitzner ${ }^{3}$ have published a theoretic analysis that regionalization of pediatric cardiac surgery is associated with reduction in surgical mortality. In the article by Checcia and colleagues, ${ }^{1}$ institutional identity is blinded, but in the Pediatric Health Information System database individual institutions are informed of their outcomes. Institution 7 is a low-volume, freestanding children's hospital in which cardiac surgery is performed as part of a regional program. The outcomes achieved at that institution (as well as the outcomes at institution 6) demonstrate that excellent outcomes can be achieved at lowvolume institutions. Evaluation of an institution cannot validly be based simply on procedure volume.

Our regional program includes 2 lowervolume institutions, as defined by the criteria used by Checcia and colleagues. ${ }^{1}$
Analysis of our outcome data for patients with hypoplastic left heart syndrome who underwent stage 1 palliation (using the right ventricle-to-pulmonary artery conduit modification of the Norwood procedure) performed between 2002 and 2005 demonstrated survival to discharge of 21 of 23 patients (91\% survival) at one institution and 8 of 8 patients (100\% survival) at the other. We believe these outcome data further support the premise that excellent outcomes can be achieved in smaller-volume institutions, particularly when the institution is part of a regional program.

Malcolm J. MacDonald, $M D^{a}$ Olaf Reinhartz, $M D^{b}$

Frank L. Hanley, $M D^{c}$

Children's Hospital of Central California ${ }^{a}$ Madera, Calif,

Children's Hospital and Research Center at Oakland $^{b}$

Oakland, Calif,

cStanford University Department of Cardiothoracic Surgery Falk CVRB

Stanford, CA 94305

\section{References}

1. Checcia PA, McCollegan J, Daher N, Kolovos N, Levy F, Markovitz. The effect of surgical case volume on outcome after the Norwood procedure. J Thorac Cardiovasc Surg. 2005; 129:754-9.

2. Mavroudis C, Jacobs JP. Congenital heart disease outcome analysis: methodology and rationale. J Thorac Cardiovasc Surg. 2002;123:6-7.

3. Chang R, Klitzner T. Can regionalization decrease the number of deaths for children who undergo cardiac surgery? A theoretical analysis. Pediatrics. 2002;109:173-81. doi:10.1016/j.jtcvs.2005.06.028

\section{Reply to the Editor:}

My associates and I appreciate the comments made by Dr MacDonald and colleagues regarding our article examining the effect of surgical case volume on outcome after the Norwood procedure. ${ }^{1}$ They raise interesting points.

We agree that individual institutions can achieve outstanding outcomes regard- 
less of volume. As they appropriately comment, the variability in survival outcome is greater in low-volume institutions. This variability highlights one of our conclusions: that the Norwood procedure is a rare operation, even in the highest-volume centers. Low-volume institutions might be unduly affected by 1 or 2 outcomes. This, however, adds credence to the efforts of an institution to improve the delivery of care in a way that will be applicable to each case.

Additionally, MacDonald and colleagues raise the pertinent issue of regional programs. Our analysis was not able to assess the effect of associations between institutions in a region. The effect on lowervolume institutions from the exposure of programs and practices developed at highvolume institutions likely has a positive effect.

Finally, we agree, as reported by Mavroudis and Jacobs, ${ }^{2}$ that many lower-volume surgeons and centers have excellent results. This highlights the need to develop processes and practices that can be adapted across institutions, regardless of the number of cases. What are the best institutions doing, and how can we learn from them? What can high-volume centers learn from the practices at low-volume centers? Sharing the details of these successful processes is essential.

Paul A. Checchia, MD, FAAP Washington University School of Medicine St Louis Children's Hospital Campus Box 8116

One Children's Place, Suite 5S20 St Louis, MO 63110

\section{References}

1. Checchia PA, McCollegan J, Daher N, et al. The effect of surgical case volume on outcome after the Norwood procedure. J Thorac Cardiovasc Surg. 2005;129:754-9.

2. Mavroudis C, Jacobs JP. Congenital heart disease outcome analysis: methodology and rationale. J Thorac Cardiovasc Surg. 2002; 123:6-7.

doi:10.1016/j.jtcvs.2005.08.035

\section{Video-assisted thoracoscopic surgery for pulmonary tuberculosis To the Editor:}

We read with interest Olgac and colleagues' remarkable experience ${ }^{1}$ with the surgical management of pulmonary tuberculosis and empyemas. The role of surgical intervention in tuberculosis has decreased dramatically with the advent of powerful antituberculous drugs. Our experience with the disease has been similar to that of the authors.Very few of the chronically collapsed lungs expand, even after drainage of the empyema and even decortication. Complication rates after resectional surgery are forbidding, with high rates of parenchymal air leaks and bronchopleural fistula. We agree with the authors that decortication is preferable to attempting resectional surgery, but we believe that this can be achieved more satisfactorily by means of video-assisted thoracoscopic surgery (VATS) rather than open thoracotomy. Patients with tuberculous empyema are frequently cachectic and emaciated, and a less invasive surgical procedure would be preferable to an open thoracotomy, with its attendant morbidity. In most cases the empyema cavity is well formed, and thoracoscopy is usually quite easy. Visualization of the empyema cavity, drainage, adhesiolysis, and decortication can be performed adequately and safely with thoracoscopy by using multiple ports.

It has been established in a metaanalysis $^{2}$ that VATS is superior to chest tube drainage with streptokinase with regard to duration of chest tubes and hospital stay in the management of pleural empyemas. VATS has the potential to be both diagnostic and therapeutic and has been established to be safe and effective. ${ }^{3}$ VATS has the potential to achieve full lung expansion in patients with trapped lung or tuberculous empyema with minimal morbidity. It is similar to open thoracotomy in that therapeutic lung resection in patients with tuberculosis is both technically demanding and potentially hazardous. ${ }^{3} \mathrm{We}$ conclude by agreeing with the authors that simple drainage and decortication would be preferable to resectional surgery in pulmonary tuberculous empyemas but affirm that this would be better achieved with VATS.

C. S. Pramesh, MS, FRCS Rajesh C. Mistry, MS Sandeep P. Tandon, MD

Division of Thoracic Surgery and General Medicine

Tata Memorial Hospital Mumbai, India

\section{References}

1. Olgac G, Yilmaz MA, Ortakoylu MG, Kutlu CA. Decision-making for lung resection in patients with empyema and collapsed lung due to tuberculosis. J Thorac Cardiovasc Surg. 2005;130:131-5.

2. Coote N. Surgical versus non-surgical management of pleural empyema. Cochrane Database Syst Rev. 2002;CD001956.

3. Yim AP, Izzat MB, Lee TW. Thoracoscopic surgery for pulmonary tuberculosis. World J Surg. 1999;23:1114-7.

doi:10.1016/j.jtcvs.2005.08.024

\section{Reply to the Editor:}

We thank Dr Pramesh and his colleagues for their comments on our recently published article. ${ }^{1}$ As clearly indicated in their letter, the authors agreed with our conclusion that the low perfusion rate alone is not an indication for lung resection under certain circumstances. However, they were also concerned about the approach we used for decortication and raised another issue, which has entirely different conceptual and technical aspects.

We have been using video-assisted thoracoscopic surgery (VATS) decortication for stage 3 postpneumonic empyemas and reported our technique recently. ${ }^{2}$ The response of the pleura is very much similar, regardless of the underlying cause (tuberculosis or nonspecific infection), in the third stage of the empyema. Calcified pleural plaques might also occur in some cases during the long and chronic course of tuberculous empyemas. Other treatment options, like deloculation and use of fibrinolytic agents, are only effective in the fibrinopurulent phase (stage 2) of the disease, and therefore their usefulness to decrease hospital stay are out of consideration for such cases that were reported in our article.

It is certain that the increased and ongoing experience with VATS will replace most of the conventional techniques and will allow us to perform more sophisticated procedures in the near future. Although Pramesh and colleagues did not mention whether they have had any experience using VATS in such cases, we think the procedure is not as easy as they stated in their letter. Because of extreme narrowing of the intercostal spaces and thickened parietal peel, introducing the thoracoports and manipulating the endoscopic instruments through these ports might be very difficult. In addition, one might have to remove a rib to enter the chest in some cases, and this could also be troublesome if conversion to an open thoracotomy as a result of severe bleeding emerges. With the gained experience over the years, we almost always know that complete expansion of the lung cannot be achieved after decortication in such 